\title{
DIGITIZATION OF THE Grand Teton National Park Herbarium
}

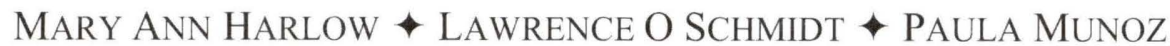 \\ UNIVERSITY OF WYOMING LIBRARIES \ LARAMIE
}

\section{$\uparrow \quad$ INTRODUCTION}

Examples of digitization projects in the history of science are understood to have lasting consequences for the intellectual history of their fields (Petersen, 2005; Roes 2001). Following this trend, herbarium collections around the world are beginning to be digitized with positive results for their institutions (Begnoche, 2002; Ong, 2002). Librarians, with their long history of making collections accessible, are participating in this trend (Foster, 2005). The University of Wyoming Libraries encourage Librarians to develop and maintain collections in a variety of subjects, and the Libraries are pursuing opportunities in digital collections. This project expands the University of Wyoming Libraries work in the digitizing of a unique collection of plant specimens.

The Grand Teton National Park (GTNP) herbarium is an historical record of the plant specimens collected in the National Park. Since the1920s, it has provided a physical record of vascular flora within the Park and includes examples of many rare and endangered species. Currently, it is housed in a converted walk-in freezer unit in an old wooden building near the Park Headquarters. It shares this limited space with storage collections of archaeological and cultural museum materials. It is available only by appointment, requires a park employee as an escort, and has no handicap access. The environment, while temperature controlled, is not ideal; there is very limited space with poor lighting. The specimens must be transported from the building to be used; there is no space to examine them in the building. The collection is not available for loan. Given this difficult access, a digital collection would be a valuable tool for Grand Teton and Yellowstone National Park employees; University of Wyoming/National Park Service Research Center investigators; University of Wyoming students, faculty and staff; Wyoming extension agents; Teton Science School faculty and students and amateur botanists everywhere. The GTNP research staff has listed herbarium management and access as a priority on their list of research projects.

A digital collection also reduces the necessity for handling the fragile specimens, helps maintain their current condition and contributes to management decisions. A digital collection expands herbarium use to local communities and extends its influence nationally.

\section{$\uparrow$ METHODS}

The initial work was done at the University of Wyoming/National Park Center Research Station (UW/NPS) in Grand Teton National Park. The photographs were taken with a Canon model EOSIDS Mark II Camera, the shutter speed was 1/25 second, aperture 16, ISO speed 100. The camera and other equipment were housed in a dedicated photography room. Specimens were transported from the Herbarium in the Park to UW/NPS, photographed and returned. Data was entered into the database, backed up on CD ROMs and sent to the server at the University Campus. 


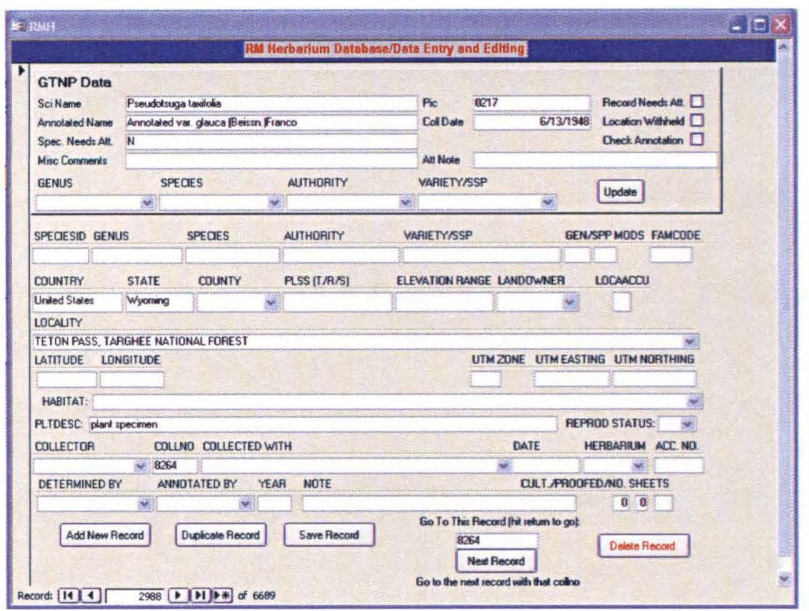

Fig. 1. Example of a page from the database.

\section{$\downarrow \quad$ PRELIMINARY RESULTS}

To date, 3,200 specimens have been photographed. The database has been transferred from the Excel file format given to us by National Park employees to relational tables in an Access database which will work with LUNA software for storing, retrieving and displaying images and their related metadata on the web. Work is continuing this winter on the database. Figure 1 is an example of a database page for a specimen. See Figure 2 for an example of a specimen photograph from the database.

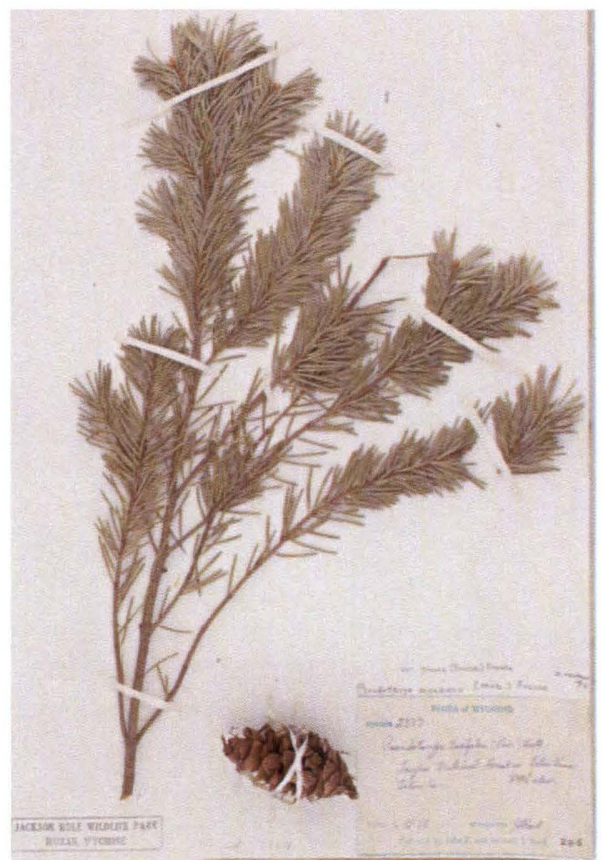

Fig. 2a. Example of a photograph of a typical mounted specimen from the GTNP herbarium.

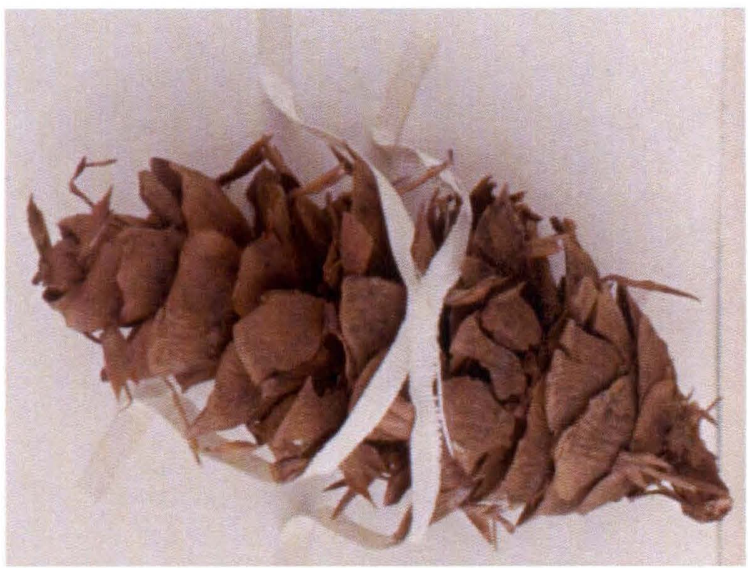

Fig. 2b Example of close up of the pine cone on the page in Fig 2a, illustrating detail.

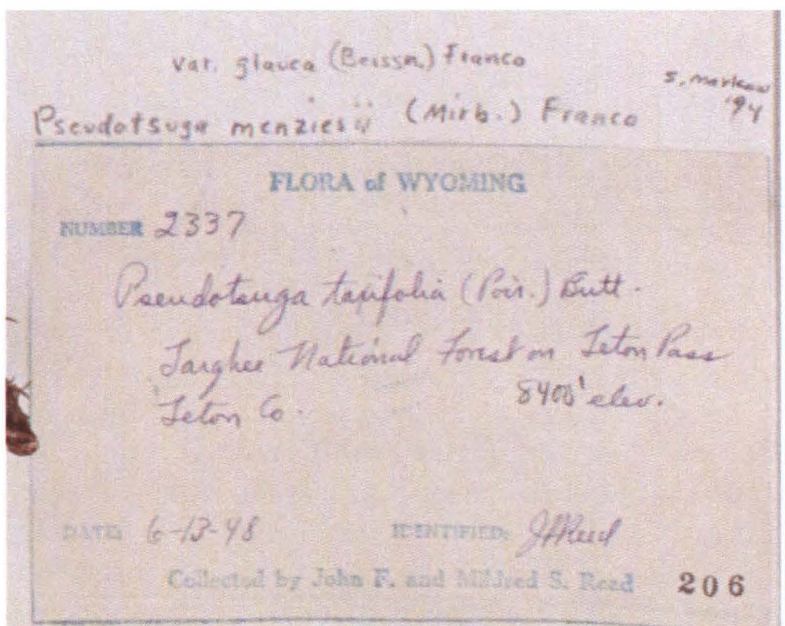

Fig. 2c Example of original label information on Fig. 2a specimen page.

Descriptive metadata, including the scientific name and collection location, was recorded in the accompanying spreadsheet as each specimen was photographed and tied to the image file with a unique identification number. Technical metadata was captured during photography, including shutter speed, aperture opening, type of equipment and imaging software used. We followed the Colorado Digitization Project (2005) best practices throughout the project.

It is the intention of the Libraries to support the database at the Laramie campus on a Library server. The project uses architecture designed to allow technology upgrades. Access images and attached metadata will be available to the public in a prevailing file format that allows a reasonable download time for the average user, such as the currently popular TIFF or JPEG formats, but may be migrated in the future as file specifications evolve. The master copy is preserved in a RAW format. 


\section{DISCUSSION}

We anticipate that the GTNP herbarium database will be available on the websites at the University of Wyoming, the Rocky Mountain Herbarium and Grand Teton National Park. In addition, the database will be marketed to extension agents, natural history associations and public schools in Wyoming. We anticipate that future editions of field guides will include a link to the collections, and we will submit our site to lists of herbaria in the United States and worldwide. We also plan to share our expertise with smaller herbaria in Wyoming, such as the UW Research Stations, the five community colleges and community nature centers.

The project will continue during the summer of 2006. The photography will be finished in the summer and the metadata completed in the fall. The final project will be brought online in 2007 .

\section{ACKNOWLEDGMENTS}

UW/NPS provided housing, financial and material support for the project. Grand Teton National Park provided access to the collection and funds for a botany student intern, Erin Foley, in the summer. We are grateful for the cooperation and encouragement of GTNP staff. We appreciate the botanical expertise contributed by the Rocky Mountain Herbarium faculty and staff, the database expertise contributed by Matt Kelly and the support received from UW Libraries.

\section{Literature Cited}

Begnoche, M. 2002. Specimens at herbarium get digital makeover. University Record Online. Available at http://www.umich.edu/ urecord/0102/Nov1 $\underline{102 / 21 . s h t m l}$

Collaborative Digitization Program. 2005. Western States Dublin Core Metadata Best Practices, Version 2.0. Available at http://www.cdpheritage.org/cdp/documents/ CDPDCMBP

Foster, N. F. and S. Gibbons. 2005. Understanding Faculty to Improve Content Recruitment for Institutional Repositories. D-Lib Magazine Available at http://www.dlib.org/dlib/january05/foster/01 foster.html

Ong, T. J., J.J. Leggett, H.D. Wilson, S.L. Hatch, and M.D. Reed. 2002. Interactive information visualization in the digital flora of Texas. In Visual interfaces to digital libraries (Vol. 2539, pp. 188-198). Berlin: Springer-Verlag Berlin.

Petersen, C. 2005. Linus Pauling and the Nature of the Chemical Bond: A Documentary History, D-Lib Magazine, Available at http://www.dlib.org/dlib/january05/01 featur ed-collection.html

Roes, H. 2001. Digital Libraries and Education: Trends and Opportunities, D-Lib Magazine Available at: http://www.dlib.org/dlib/july01/roes/07roes. $\underline{\mathrm{html}}$ 